\title{
Sentirse en casa \\ Ariadne: un proyecto para la inclusión de personas migrantes a través del arte
}

\author{
Marián LÓPEZ FDZ. CAO ${ }^{1}$ \\ macao@edu.ucm.es
}

Recibido: $18 / 10 / 12$

Aceptado: 22/11/12

\section{RESUMEN}

Este artículo explica las bases de la mediación a través del arte con migrantes. Expone las principales tendencias en la mediación intercultural y el papel del arte como motor de mejora personal y como motor de trasformación. A partir de ello, explica los principales objetivos que el proyecto "Sentirse en casa" abordó desde los diferentes talleres de arteterapia, en el marco del proyecto Ariadne, dentro del programa Grundtvig, Life Long Learning de la Comunidad Europea y en el que ha participado el Grupo de Investigación Consolidado $941035^{2}$ “Aplicaciones del Arte en la Integración Social: Arte, terapia y educación para la inclusión” de la Universidad Complutense de Madrid.

Palabras clave: Arte. Arteterapia, Inclusión social. Migración.

\section{Referencia normalizada}

López Fdz. Cao, M. (2012). "Sentirse en casa. Ariadne: un proyecto para la inclusión de personas migrantes a través del arte". En Arteterapia: Papeles de arteterapia y educación artística para la inclusión social Vol.7: páginas 121-141. Madrid. Servicio de publicaciones UCM.

\section{SUMARIO}

De dónde venimos: redefiniendo puntos de partida. Abordaje desde la actividad artística. La experiencia. Referencias bibliográficas.

\section{Feeling at home}

\section{Ariadne: a Project for migrant people through art}

\begin{abstract}
This paper explains the basis of mediation throughart with migrants. It sets out the main trend sof intercultural mediation and the role of art as an mean sof personal improvementand personal transformation. Based on this statement, the paper explains the main objectives that the project "Feeling at home" addressed different art therapy workshops, in the frame work of the Ariadne project, with in the Grundtvig, Life Long Learning program supported by the European Community and in which the 941035 consolidated research group "art applications in Social integration: art, therapy and education for inclusion" of the Complutense University of Madrid has actively participated.
\end{abstract}

\footnotetext{
${ }^{1}$ Directora del grupo de investigación consolidado 941035“Aplicaciones del Arte en la Integración Social: Arte, terapia y educación para la inclusión”. Universidad Complutense de Madrid.

${ }^{2}$ Colaboradoras en el desarrollo de los talleres: Ana Serrano, Ana Rosa Sánchez Velasco, Esther Carmona, Carolina Peral, Berta de la Dehesa y Tania Ugena. Sin ellas, este proyecto no hubiera sido posible. Gracias también a Laura Rico que, viendo que teníamos metas y anhelos comunes, se unió a él y nos enriqueció con su experiencia.
} 
Keywords: Art. Art therapy. Social Inclusion. Migration.

\section{CONTENTS}

Where we come from: redefining starting points. Approach from artistic activity. Experience. References.

"Las migraciones manifiestan lo que está oculto e irresuelto; detrás de la decisión de inmigrar hay procesos estructurales y elecciones colectivas; detrás del racismo está el miedo al diferente, detrás del indocumentado está la crisis del Estado-nación, detrás de los flujos migratorios está la falta del instituciones mundiales para la gobernación de un mundo único e interconectado, detrás de las expulsiones está la vigencia efectiva de los derechos humanos; detrás de la inmigración selectiva está la viabilidad del Estado de Bienestar"

(Joaquín García Roca, La persona más allá de la migración, 2000: 17)

Este proyecto se articula sobre la migración desde un enfoque psicosocial y apuesta por el valor del arte como apoyopara articular y mejorar el proceso que conlleva el acto de migrar. Se centra asimismo en lo que suponen los procesos identitarios en constante cambio y cómo son influenciados y agudizados por los movimientos migratorios.

El enfoque psicosocial que planteamos aborda, de acuerdo con Martínez Roca, los procesos migratorios, que arraigan tanto en causas estructurales, como en las decisiones individuales que explican un itinerario migratorio concreto (Martínez Roca: 2000, pp. 18). Es decir, cómo el ser humano es a veces representante y consecuencia de una situación política, económica, educativa y/o sociocultural, pero también cómo, dentro de ese proceso, tiene y ejerce la capacidad de elegir sobre parte de su destino y lo convierte en relato que conforma su construcción identitaria. Como señalaba Sartre, el ser humano, con lo que los demás han hecho de él, es lo que quiere ser, lo que implica ser afectado y ser consciente de la situación que vivimos pero poder construir, sin ingenuidad, un proyecto de vida. Cómo Martínez Roca señala: "el emigrante es tanto un paciente de su desplazamiento, como un agente que decide desplazarse para alcanzar aquello que valora y la forma de procurarlo. Las personas migrantes son sujetos que piensan, deciden y actúan pero son también actores que recitan los papeles que se les asignan históricamente" (ibídem ant.) este enfoque aboga por una desnaturalización del concepto inmigrante y una humanización que reconoce que los extranjeros son personas, hombres y mujeres, y que nosotros somos extranjeros, o podemos serlo. Parte de un enfoque que tiene en cuenta al ser humano como resultado y parte de los contextos sociales, económicos y políticos globales, pero también de la capacidad que late en cada sujeto singular para elegir y vivir su futuro, siempre condicionado, o sucumbir a un proceso de vulnerabilización social.

Desde este enfoque nos concentramos en la vida humana como centro de interés y en la creación de habilidades, y oportunidades reales que busca favorecer capaci- 
dades para elegir la vida humana que cada uno decida y no tanto gestionar simples recursos.

\section{DE DONDE VENIMOS: REDEFINIENDO PUNTOS DE PARTIDA}

\subsection{De La perspectiva participativa a Los conocimientos situados y los suje- tos encarnados}

"La topografía de la subjetividad es multidimensional; por ello, es una visión. El saber de uno mismo es parcial en todos su ámbitos, nunca acabado, completo, simple u original; es siempre construído y unido de modo imperfecto, y por ello susceptible de ser unido de nuevo con otros elementos, de ser visto de otro modo sin ser otro" (Haraway. D. Simians, Cyborgs and Women: The Reinvention of Nature (New York; Routledge, 1991. Traducción de la autora) ${ }^{3}$

A partir de los análisis de Montenegro y Pujol (2003: 295-307) podemos señalar que desde la perspectiva participativa, las personas afectadas por problemas sociales protagonizan, a través de su participación, la propia definición de aquello problemático y de las vías de solución posibles. Las perspectivas participativas proponen una solución al problema de cómo actuar sobre la realidad para transformarla. Sobre la base de este conocimiento se formulan y llevan a cabo acciones de transformación de los problemas que atañen a las personas de la comunidad. Este acercamiento parte de una postura representacionista del conocimiento al postular una realidad susceptible de ser descubierta a partir de un proceso de problematización y desvelamiento que, finalmente, permitirá sentar las bases para las acciones de transformación social.

Sin embargo, y siguiendo con el análisis de estos autores, el construccionismo social por el que nos decantamos en este proyecto, da un paso más y rechaza que el conocimiento sea una percepción directa de la realidad: "los términos y las formas por medio de las que conseguimos la comprensión del mundo y de nosotros mismos son artefactos sociales, productos de intercambios situados histórica y culturalmente y que se dan entre personas" (Gergen, 1994, p. 73). El significado, según este enfoque, es visto como algo que deriva de intercambios microsociales incrustados en el seno de amplias pautas de vida cultural. Esta corriente afirma que no hay maneras en las que la realidad pueda ser percibida objetivamente. Proponen, por el contrario, que nuestros conceptos son fundamentalmente producidos socialmente, a través del lenguaje, en comunicación con otras personas (Spears, 1997).

\footnotetext{
${ }^{3}$ The topography of subjectivity is multi-dimensional; so, therefore, is vision. The knowing self is partial in all its guises, never finished, whole, simply there and original; it is always constructed and stitched together imperfectly, and therefore able to join with another, to see together without claiming to be another (Haraway. D. Simians, Cyborgs and Women: The Reinvention of Nature (New York; Routledge, 1991)
} 
Ello sin embargo podría llevar a un relativismo que impediría la transformación o la intervención social. Frente a ello o dando un tercer paso más en el compromiso humano nos situamos en la definición de los "conocimientos situados". Los conocimientos situados, acuñados por Donna Haraway son encarnaciones (y visiones) en las que la posición desde la cual se "mira" define las posibilidades de lectura y acción. Es decir, permite posicionamientos en que sólo algunas verdades son posibles. Gracias a esta posición se pueden establecer conexiones parciales con otros agentes para construir el conocimiento.

Así pues, nuestro enfoque se sitúa en cómo el conocimiento es una construcción y supone una localización precisa desde un sujeto que se sabe situado, que mira desde un punto de vista y plantea propuestas con otros agentes sociales para una mejora del bienestar y la vida.

\subsection{El enfoque desde la psicología cultural}

Existen varios modelos que encaran las situaciones migratorias y que en general tratan de buscar una mejora en la vida tanto del grupo que llega como del grupo social queacoge. Sin embargo, dependiendo del modelo, algunos autores ponen el énfasis en las capacidades de ajuste del grupo migrante por encima de las capacidades de cambio y ajuste del grupo originario.

\subsubsection{El modelo de Berry}

La aculturación es definida por Berry como el proceso de cambio cultural y psicológico que tiene lugar como resultado del contacto entre dos o más grupos culturales y sus miembros. Las estrategias de aculturación tienen dos componentes relacionados: la actitud (preferencia del individuo sobre cómo llevar a cabo el proceso de aculturación) y la conducta (las actividades que lleva a cabo la persona). El modelo de Berry sin embargo se centra en exceso en las decisiones individuales y no tiene en cuenta las asimetrías de poder y presenta al grupo de inmigrantes con libertad en la elección de su estrategia de aculturación.

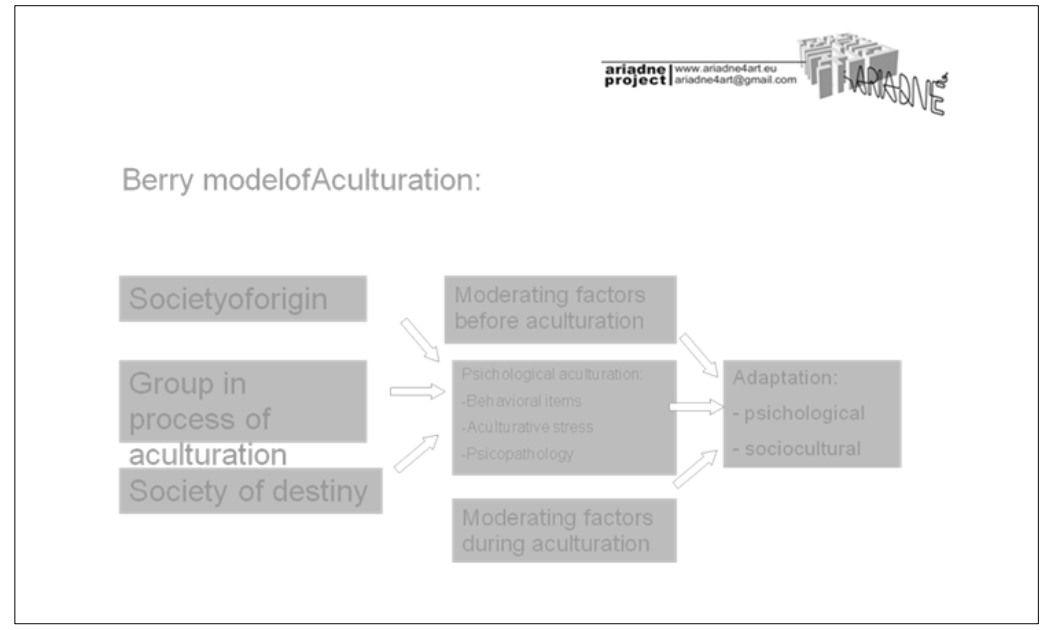




\subsubsection{El modelo de Gudikunst}

La Teoría de AUM (AnxietyUncertanty Management) (Gudykunst, 1988,1993, 1994, 1995; Gudykunstand Hammer, 1988; Gudykunstand Kim, 1997; GudykunstandSudweeks,1992) puede utilizarse para diseñar programas de capacitación para ayudar a los nuevos facilitadores culturales a mejorar su comunicación o adaptarse a nuevas culturas. Teoría de AUM se basa en la suposición de que gestionar la incertidumbre y ansiedad es suficiente para la comunicación efectiva y el ajuste intercultural. Cuando se aplica la teoría de AUM al ajuste intercultural, el argumento es que la causa básica de la capacidad de ajuste reside en la habilidad de los migrantes para gestionar su incertidumbre y ansiedad en la cultura de acogida. Cuando los migrantes pueden manejar su ansiedad e incertidumbre se sienten cómodos en la cultura de acogida.

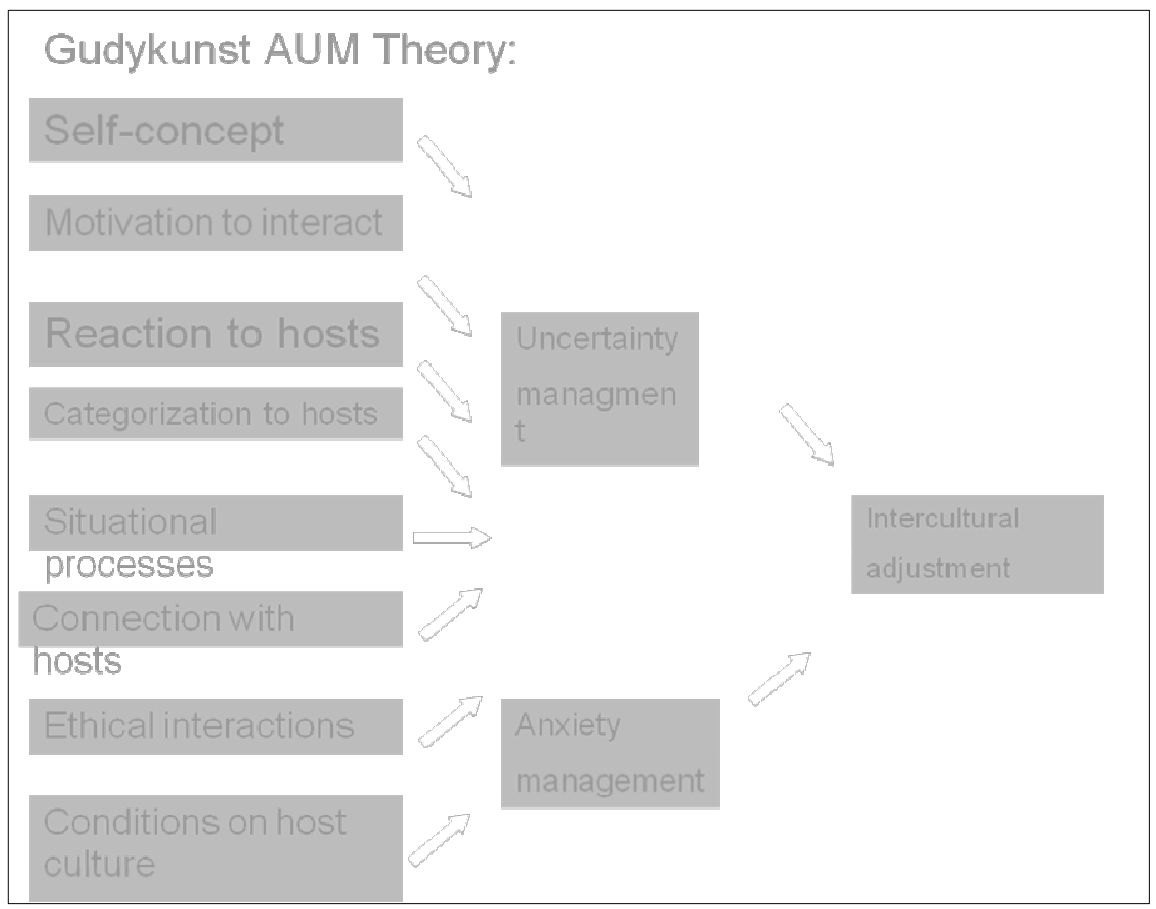

Este modelo, sin embargo, enfatiza, al igual que el modelo de Berry, la adaptación y ajuste de los grupos migrantes frente a los grupos receptores, que parece no necesitar acomodarse o adaptarse.

\footnotetext{
1.2.3. El modelo Interactivo de Aculturación -IAM- (Bourhis, Möise, Perreault y Senécal, 1997)

Este modelo tiene en cuenta la perspectiva de la población nativa y la sitúa en el mismo plano que la de la población inmigrante, abordando la integración en su globalidad. En función de las estrategias desarrolladas por cada grupo se darán una
} 
relaciones u otras entre ellos, que van desde el polo consensual (cuando coinciden) hasta el polo conflictivo (cunado son incompatibles).

\subsection{El modelo de aculturación desde la Psicología de la Liberación (PL)}

La Psicología de la Liberación se basa en un modelo ecológico-comunitario. Ello implica analizar las condiciones de opresión y liberación a diferentes niveles, que están no obstante interconectados, de modo que un cambio en cualquier nivel provocará un cambio en los demás. Ello implica un abordaje a tres niveles: comunitario, relacional y personal.

\subsubsection{La identidad como proceso complejo: el yo narrado o las narrativas del yo}

"Caben cuatro modos de conjugarse al ser: lo que se desea ser, lo que debe ser, lo que es, lo que puede ser" (Fiorini, H. 1995: 11)

El proceso de aculturación implica mucho más que una "mudanza cultural". Más bien, lleva consigo cambios profundos en las identidades personales. Ello se pone en relación con diferentes ámbitos de la vida del individuo, es decir, la identidad cultural que implica no sólo la identidad individual sino la identidad de género, grupal y, en general, todos los ámbitos de las identidades (129).

Como señala la filósofa M. Luisa Femenías, debemos preguntarnos si es posible hablar de la existencia de las esencias culturales o identitarias, y si existen, si podemos hablar de identidad y diferencia. Como señala esta autora:

"Unos entienden que el antiesencialismo es verdaderamente escéptico y negativo; estos consideran que todas las identidades son inherentemente represivas y todas las diferencias inherentemente excluyentes. Otros, en cambio, lo ven celebratorio y positivo. Desde ese punto de vista, todas las identidades merecen reconocimiento y todas las diferencias son dignas de afirmación. ¿Evaden ambas perspectivas enfrentadas a la cuestión crucial de qué afirmaciones de identidad se vinculan a la defensa de relaciones sociales de igualdad? ¿Cuáles no? ¿Cuáles pueden expandir la democracia? ¿Cuáles trabajan en contra de la democratización de la sociedad? (Femenías, M.L: 2007, pp18)

En definitiva, pensar si la construcción del proyecto vital humano viene predeterminado por una identidad asignada, sea esta cultural, social de género, clase o étnica, y si debemos tomar el concepto de identidad como un constructo cerrado al que debemos dirigirnos o de donde debemos partir. Ello nos lleva a definir también las sociedades y las culturas como grupos de individuos con prácticas socioculturales cerradas e inamovibles, o como procesos de permeación y transformación permanente y si ellas son, como señala Femenías, coherentes con los principios de igualdad y respeto entre seres humanos. De acuerdo con la perspectiva construccionista y que se centra en los conocimientos situados, podemos definir también la 
identidad, como un proceso en construcción y negociación permanente y como una narrativa del ser.

Jerome Bruner (1996) considera al yo como a un "enjambre de participaciones", producto de las situaciones en las que la persona participa. Una de sus características, siguiendo a Bruner, es su estructura narrativa, que él mismo denomina el "yo historiado". Esta descripción que se hace del yo varía, sin embargo, en función del interlocutor para el que se crea el relato. Es el yo dramatúrgico (Goffman, 1986). Podríamos decir (de la Mata, M. García Ramírez, M., Santamaría Santigosa, A.; Garrido, R , pp 130) que el yo es contingente con el rol que uno está desempeñando, con los múltiples roles que uno desempeña, y no todos son susceptibles de ser interpretados simultáneamente. El yo, por tanto, no es una identidad cuya existencia pueda separarse de las dinámicas de percepción, relación interpersonal y cognición. Es una construcción social y cultural al que se le añaden además posiciones "dialógicas" en las que el individuo encuentra o se encuentra o define en diferentes posiciones o roles.La configuración de la subjetividad es por ello, tanto un proceso como una actividad abierta y cambiante, lo cual exige re-mediaciones y renegociaciones contínuas con el medio material y sociocultural. La identidad es pues una actividad abierta y actualizada a cada paso, es un acontecer temporal (ibídem, 132). Desde este punto, nuestro proyecto aborda la identidad como un proceso dinámico en el que el individuo busca un sentido a su existencia e, influido por la cultura de origen, de llegada, por la comunidad de origen y llegada, por sus creencias y constructos cognitivos, heterodesignaciones de género, clase y origen, elige aquellos elementos que le proporcionan seguridad y le ayudan a construir un proyecto de vida.

Una vez señaladas algunas de las posturas que abordan la intervención en procesos migratorios, nos preguntamos qué puede suponer la actividad artística en todo ello: como vía de análisis, como medio de percepción de la realidad y como camino de trasformación personal y vínculo social.

\section{ABORDAJE DESDE LA ACTIVIDAD ARTÍSTICA}

\subsection{Qué ofrece el arte a la inclusión social}

El proceso artístico pone en juego al ser en un proceso de desindentificación y reconstrucción constantes. El arte, la actividad artística, facilita la salida de la experiencia interna y de los sentimientos y permite la continua renegociación de los mismos. Los materiales artísticos ofrecen un modo tangible y estable a través del cual se pueden encarar conflictos de modo estético y a su vez expresar los aspectos conscientes e inconscientes a través de la expresión visual.

El arte, a través del proceso de interiorización/exteriorización, permite el trabajo con las imposiciones externas e internas y facilita la expresión de las emociones que se niegan fuera del espacio de la creación: permite la contradicción, la paradoja, la frustración y la rabia, del mismo modo que permite el perdón, la reconciliación y el 
duelo. Por ello es un proceso adecuado para el cambio y la reflexión sobre el mismo. El arte permite el lugar de lo indecible, donde silencio y palabra se encuentran.

Como señala la arteterapeuta Joy Schaverien

"Las pinturas, incluso cuando aparecen aparentemente terminadas, evocan movimiento y relación, pero no pueden ser leídas. Los mapas pueden ser leídos, en los mapas las figuras y las marcas no significan necesariamente algo más allá de sí mismos. Incluso una imagen bidimensional es tridimensional en el sentido de que está llena de múltiples significados potenciales que reverberan y hacen eco entre sí. Ninguna pintura puede ser explicada totalmente a través de la palabra; si así fuera, no tendríamos ninguna necesidad de hacerla. (Schaverien, 1989)

El proceso de buscar el sentido a una imagen viene apoyado o ayudado por el hecho de que su forma concreta sobrevive, dura más que la experiencia de la realización. Una pintura no se evapora como un sueño, aunque algún sueño continúe con nosotros durante horas en la vigilia. A veces se tiene la experiencia de despertarse en medio de la noche y querer volver atrás y continuar soñando lo anterior. Pintar una imagen puede interrumpirse del mismo modo pero puede retomarse, aunque algo se haya alterado en la interrupción. Incluso puede suceder que una persona haga una asociación particular cuando lo está realizando, y luego haga o surjan otras. Por ello, como señala Eherenzweig (1967) " el análisis del arte continua allá donde el análisis del sueño termina". La obra de arte, delante de nosotros, en su fisicidad nos ayuda a comprender nuestros cambios, nuestras reacciones, nuestras negociaciones con nuestra pretendida o buscada identidad.

La pintura, la expresión artística ofrece un modo de exteriorizar los sentimientos que hace que tengan vida propia, más allá de los recuerdos y los sueños, aunque estos estén a veces presentes en las imágenes

\subsection{Qué ofrece el espacio y el tiempo del arte. Los espacios/tiempos del arte como "base segura" y reinauguración del vínculo.}

El espacio donde se produce la actividad artística es un lugar de pruebas, de experimentación, de negociación, por ello debe conformarse como un espacio de seguridad que permita la libertad.

El espacio de taller que se ofrece a los otros es un espacio calificado como especial. Por ello, además de la importancia de la actividad artística, cobra importancia el espacio del arte y el tiempo del arte.

A partir de las teorías del apego podemos concluir que el espacio de la actividad artística en ámbitos sociales debe convertirse o reinaugurar un espacio donde el ser encuentre una seguridad que permita la reflexión, la introspección, el humor y la acción transformadora.

El apego, acuñado por Bowlby, y ampliamente desarrollado por las teorías sobre el afecto y la intersubjetividad, se define como un lazo afectivo que une la persona a una figura específica (figura de apego). Este comportamiento de vinculación, resultado tanto de una necesidad innata como de adquisición, tiene doble función:

1. Una función de protección física y seguridad emocional proporcionada por un adulto capaz de defender al niño vulnerable de todo peligro; y 
2. Una función de socialización. El comportamiento de vinculación con la madre/padre se diversifica, se amplía a figuras auxiliares, se desplaza, a lo largo de la vida, a las personas próximas, luego a los extraños y, finalmente, a grupos cada vez más amplios, que estructuran la personalidad.

Dentro de este modelo, los afectos sirven para:

1. Evaluar las condiciones internas y externas del individuo;

2. Decidir, actuar y evaluar continuamente sus consecuencias; y

3. Comunicarse con otras personas (Bowlby, 1969).

Bowlby considera que "el apego íntimo a otros seres humanos es el eje alrededor del cual gira la vida de una persona, no sólo cuando ésta es un infante o un niño..., sino también durante toda la adolescencia, los años de madurez y la senectud. De esos apegos íntimos una persona extrae su fuerza y experimenta el goce de la vida y en la medida en que contribuye a ello depara fuerza y goce de la vida a los demás." (Bowlby, 1980, p.445).

Bowlby da como norma básica la indicación de que el terapeuta debe constituirse en figura de apego sereno para su paciente, ser una "base segura" desde la cual se desarrollará el difícil y largo proceso psicoanalítico.

Tomando el concepto de "base segura", y trasladando la figura del terapeuta al educador artístico, arteterapeuta o facilitador social a través del arte, señalamos que esta persona, acompañante en definitiva del proceso creador del o la migrante, debe proporcionar una "base segura" para que las personas puedan convertir un espacio desprovisto de categorías específicas, en un "espacio potencial", que genere objetos transformacionales, en palabras de Winnicott.

El espacio que ofrecemos incluye pues, algunos de los elementos que señalan los teóricos del apego:

- la comunicación y la comunión. La comunicación tiene un propósito de informar y cambiar al otro, mientras que la comunión simplemente comparte. El proceso de compartir estados afectivos es el rasgo más general y clínicamente más pertinente del relacionamiento intersubjetivo.

- Entonamiento afectivo. Daniel Stern llama entonamiento afectivo (o sintonía afectiva, resonancia afectiva, responsividad empática, apareamiento afectivo) a la capacidad de la madre/padre de comprender y reflejar especularmente las emociones de su infante. Así el acompañante de la actividad artística debe buscar una "entonación afectiva" con el grupo, con el individuo que acude al taller, de tal modo que la creación, y la transformación, sean posibles.

- Momentos de encuentro. Stern y col. (1998), consideran que gran parte de los efectos terapéuticos duraderos tiene lugar dentro del conocimiento relacional implícito compartido entre el paciente y el analista (aquí podríamos sustituir entre el facilitador y el migrante), como resultado de "momentos de encuentro" que inducen cambios en este campo relacional intersubjetivo, o sea no verbal, no interpretativo. Son cambios diferentes de los cambios producidos por la interpretación que 
hace consciente lo inconsciente. Son cambios que afectan a la creación, a su relación con el entorno y que, posteriormente permean los ámbitos de la consciencia.

- Seguridad y confianza. Los sentimientos de seguridad y de confianza permiten asociaciones libres con la experiencia del presente y del pasado. Progresivamente se van activando los esquemas emocionales del self en relación con los otros que son importantes (Emde).

- Nuevos comienzos. Las experiencias afectivas en el aquí y el ahora adquieren una nueva relevancia y se hacen posibles "nuevos comienzos" (Balint, 1967) o reorganizaciones de estos esquemas. Nuevos componentes y configuraciones emocionales suelen emerger en nuevos contextos de relaciones y, sobre todo, en el proceso psicoanalítico. Los nuevos comienzos necesitan de sintonía afectiva del analista con el paciente. Las influencias integradoras de los procesos afectivos en psicoanálisis operan principalmente en forma no consciente. La disponibilidad emocional del acompañante dentro del proceso de creación puede permitir al migrante "experiencias emocionales correctoras" con sentimientos de "nuevos comienzos".

\subsection{La imaginación situada}

'Si no se puede bailar, no es mi revolución" Emma Goldman

StoetzlerandYuval-Davis en su artículo "Teoría del punto de vista, conocimiento situado y la imaginación situada" ("Stand point theory, situated knowledge and the situated imagination")(2002) señalan a la imaginación como un elemento crucial que une simultáneamente categorías epistemológicas y sociales. Un elemento que pone en relación conocimiento con experiencia social y corporal. Castoriadis señala que cada sociedad como conjunto y cada institución social así como cada práctica específica está basada en un "imaginario social", retomando la idea formulada por Spinoza de que en el corazón de la política está la emoción, el deseo, el afecto, que son tanto de componentes corporales como de sociales. Marcuse y otros autores señalan que, para cambiar la realidad de una sociedad específica, la imaginación y la fantasía son recursos esenciales. Adorno es un defensor de la imaginación: la mente necesita transformar, no rechazar, su cuerpo, su miedo y su deseo; la imaginación, al igual que la memoria tiene trazos del contexto social del conocimiento y constituye asimismo el camino para un posible cambio (2002: 324)

Al igual que el lado cognitivo del proceso mental, el lado imaginario está conformado por muchos aspectos de cruce y dimensiones sociales individuales. El lado imaginario está conformado por la contradictoria unidad que forma 'lo social' y 'el individuo'. Un examen de la historia del concepto de imaginación muestra que siempre el discurso dominante tiende a limpiar las 'impurezas' de lo corporal, lo irracional y lo contextual al intelecto y se concibe unilateralmente de forma indivi- 
dualista, racional y universalista (una tendencia moderna en la que normalmente se invoca la afirmación cartesiana de un dualismo estricto cuerpo-mente). La imaginación seha ofrecido en cambio como un refugio conceptual para el potencial humano para el cambio social. El concepto de imaginación ha sido utilizado como una herramienta conceptual que permite a la sociedad por un lado y al cuerpo, por otro lado (esto es al grupo y al individuo), formular y articularnuevos objetivos sociales, valores y significados. Tiene lugar, por lo tanto, en el proceso de negociación mental entre las contradicciones de la experiencia y la percepción, así como entre lo que 'es' y lo qué 'debe ser'(Stoetzlerand Yuval-Davis, 327)

Así la imaginación se convierte en un elemento básico del ser y su relación consigo mismo y con lo social, traspasa o atraviesa lo cognitivo a la par que lo emocional y lo corporal apuntando a un universo posible, más allá del próximo. El concepto de imaginación "situada" apunta a su función, dentro de un locus o espacio determinado, en el que operar. Más allá de la fantasía, que nos puede ayudar a evadirnos de un presente aterrador, la imaginación situada trabaja las posibilidades de cambio dentro del aquí y ahora, propiciando el pensamiento divergente y la resolución creativa de los conflictos.

El ámbito de la actividad artística propicia la imaginación, al abrir la mente a la emoción, lo posible y el cambio. Amparado por un ámbito afectivo que propicia el vinculo, los talleres de arte para la inclusión social se abren a la reflexión sobre el ser en el pasado, presente y futuro y sus vinculaciones con el otro y el mundo. Los talleres del proyecto que presentamos, forjado sobre estas bases epistemológicas conectan directamente con una imaginación situada que traza ejes transversales hacia la comunidad desde la propia y fluida subjetividad, desde el cuerpo a la par que desde el pensamiento. Que imagina una sociedad, que tiene la capacidad de articular una imaginación encarnada en un aquí y ahora, en un sujeto, pero que también puede pensar como grupo con valores comunes. Recupera la fuerza emancipatoria de Marcuse y Adorno y el potencial de Castoriadis. Y busca dar sentido al ser que se inserta en una nueva situación.

\section{LA EXPERIENCIA}

Tras la búsqueda de documentación teórica que nos aportara la seguridad de encontrarnos con unas bases seguras para encarar el proyecto de desarrollo humano a través del arte con personas que migran, decidimos ponernos como objetivos algunos de los conceptos que habíamos encontrado en las distintas experiencias previas y habían sido ratificadas por las investigaciones consultadas.

3.1. Los objetivos que pretendíamos tratar tenían que ver con:

\subsubsection{La Incertidumbre y la ansiedad}

La psicóloga social Vareghi señala que un nuevo entorno es por definición no descifrable, no predecible y no completamente previsible. Si los cambios de vida están repletos de factores potencialmente estresantes, la distancia cultural se agrega 
a la angustia, por lo que los aspectos emocionales son un tema central en la literatura de ajuste intercultural o cross-cultural (Varieghi, V. ).

El concepto de incertidumbre, manejado por Gudykunst es de especial relevancia en los momentos de cambio social e individual y el proceso creador puede ayudar a fomentar las capacidades que no sólo toleran, sino se aprovechan de los beneficios de la tolerancia a la incertidumbre.

La hoja en blanco en el acto creador es una prueba de nuestra capacidad de enfrentarnos a lo nuevo, y nos convoca a una múltiple variedad de decisiones posibles en cuanto a ella. Saber asumir el reto del vacío, de la no respuesta cerrada e inmediata, de la duda, de que las decisiones que vamos tomando son eventuales y no duraderas pero pueden cambiar nuestro destino, permite convertirse en seres que aceptan el cambio y la duda como ejes de su propio devenir y que ese cambio no le genera la ansiedad de la falta de control sobre el propio destino. Dibujar es saber que cada línea cambia la anterior y cada trazo modifica los realizados. Dibujar implica arriesgarse a equivocarse y a tener que comenzar de nuevo. Soportar la ansiedad del caos creador, acostumbrarse a la duda puede generar en las personas un modo diverso de proceder también en la vida.

\subsubsection{Resiliencia, estrés y vulnerabilidad}

La resiliencia refiere a la capacidad de enfrentarse a las dificultades, a la resistencia al trauma y a la adaptabilidad ( Sayed-Ahmad Beiruti, N. 2010: 273). Es la capacidad de mantener un proceso de crecimiento y desarrollo suficientemente sano y normal a pesar de las condiciones de vida adversas. Es un concepto tomado de la física, donde la resiliencia es la elasticidad de un material, su tendencia a oponerse a la rotura por un choque.

La resiliencia implica la conjunción de sentimiento y temple para elaborar satisfactoriamente las dificultades tanto en el plano individual como interpersonal. Es, según Cyrulnic "la capacidad de una persona o de un grupo para desarrollarse bien, para seguir proyectándose en el futuro a pesar de los acontecimientos desestabilizadores, de condiciones de vida difíciles y de traumas a veces graves"(Cyrulnic, 2003, en Sayed-Ahmad Beiruti, N. 2010: 274).

Los factores de protección o resilientes frente al trauma, violencia y pérdida, son aquellas variables que operan para mitigar el riesgo. Se consideran fuerzas internas y externas que contribuyen a que la persona o la familia resistan o aminoren los factores de riesgo. Sayed-Ahmad Beiruti señala:

1. La satisfacción de las necesidades afectivas, que facilitan al sujeto la creación de relaciones con su entorno natural y humano y de pertenencia a una red social, mediante el establecimiento de unos vínculos afectivos, familiares y sociales, de buena calidad, estables.

2. La satisfacción de la necesidad de vincularse.

3. La aceptación, la consideración y el reconocimiento, por parte del entorno humano próximo y significativo, que proporciona al sujeto un espacio suyo, donde se siente aceptado e importante y donde podrá a empezar a aceptar a los demás. 
4. La satisfacción de las necesidades sociales, la necesidad de sentirse parte de la comunidad, desarrollar un sentimiento de pertenencia.

5. La comunicación. Gracias a la comunicación, los individuos reciben todos los contenidos informativos indispensables para situarse en su propia historia y en el contexto social y cultural que le son propios.

6. La participación activa en las estructuras sociales.

(Sayed-Ahmad Beiruti, N. 2010: 276)

A veces, continua Sayed-Ahmad Beiruti, la resiliencia no es posible porque los recursos internos no fueron bien fortalecidos (falta de estabilidad afectiva, falta de vínculos seguros, entorno con riesgo de maltrato, problemas graves del desarrollo); porque la intensidad y la duración del trauma han afectado demasiado al sujeto; o porque el entorno no proporciona a la persona el apoyo, la acogida y el apego suficientes (ibídem, 277).

El proceso creador reinaugura, o puede reinaugurar, un espacio de apego. En él, a través del espacio potencial, arropado por un/a facilitador/a que inicia un vínculo de confianza plena y que se sitúa "para el otro", el sujeto puede comenzar, a través del "entonamiento afectivo", "la comunión", la "seguridad, la "confianza" y los "momentos de encuentro" que ya hemos definido en líneas anteriores, un "nuevo comienzo", un relato creador que de sentido a su vida.

\subsubsection{La pérdida. El Duelo}

El duelo habitualmente se entiende como el conjunto de procesos psicológicos y psicosociales por la pérdida de un ser querido o una abstracción (patria, objetos, paisajes, etc.) al cual se estaba efectivamente vinculado, que ponen en marcha un proceso de reorganización de la personalidad y de adaptación a la nueva realidad. El duelo migratorio supone mantener y reelaborar vínculos con los objetos perdidos, así como adoptar y desarrollar nuevos vínculos con la sociedad de acogida (ibídem, pp. 270). El Síndrome de Ulises es una de las enfermedades asociadas por el cual la persona no puede hacer vida normal y simbólicamente sigue aferrada a una vida perdida que no puede recuperar.

En el duelo migratorio no se pierde un solo objeto, la pérdida es múltiple, de personas y de abstracciones. El individuo que migra pierde a la familia y los amigos, el estatus social, su proyecto vital, la lengua y la cultura, el grupo y el sentimiento de pertenencia, la tierra y los paisajes, etc. Todo lo cual exige al sujeto un trabajo de duelo con emociones amplificadas en su intensidad y ambivalencia (ibídem, 271). Es un duelo mixto por pérdida (estatus social, proyecto vital,...) y por separación (familia, amistades, etc.)

La elaboración del duelo "permitirá integrar de manera discriminada los dos países, los dos tiempos, el grupo de antes y el grupo actual, que dará lugar a la reorganización y consolidación del sentimiento de identidad, que corresponderá a alguien que sigue siendo el mismo a pesar de los cambios y modelaciones" (Grinberg y Grinberg, 1984, en Sayed-Ahmad Beiruti, N. 2010: 273) 
El proceso creador permite la elaboración del duelo a través de las terapias narrativas. En ellas, el ser, a través del recuerdo, resitua su vida pasada y da sentido, o trata de buscarlo, a la nueva situación, intentando dar continuidad a su existencia. El trauma migratoria escinde el ser, impide el proyecto. La construcción de nuevos relatos tratan de desbloquear el proyecto, dando sentido a lo acaecido.

\subsubsection{Disonancia y decepción. Tolerancia a la frustración.}

Uno de los aspectos que queríamos trabajar, relacionado con el duelo, era el duelo de las propias expectativas: del lugar, de sus gentes, del ser mismo cuando ve que sus capacidades y potencialidades no se desarrollan del modo en que habían proyectado, o cuando observa que aquellas capacidades por las que era valorado en otro tiempo y territorio, no son valoradas o tenidas en consideración.

La actividad artística es una estupenda metáfora de la decepción: el resultado nunca coincide con lo esperado, la mano no responde a lo proyectado, el pincel no sigue nuestras expectativas, el agua corre demasiado rápido o el papel absorbe la tonalidad degradada que esperábamos. Enfrentarnos a nuestra obra es, de algún modo, enfrentarnos también a nuestras limitaciones: aceptarlas, asumirlas, vivir con ellas.

\subsubsection{Volver a sentirse "uno/a mismo/a"}

Como señala Vareghi, "El conflicto de identidad se despliega en desintegración, que es seguido por la reorganización y auto-renovación. El proceso incluye la integración de los cambios en los patrones habituales de respuestas cognitivas, afectivas y conductuales que tienen como consecuencia un estado de salud funcional con el nuevo entorno y puede llevar a una "identidad intercultural". Esta es una condición donde "la identidad cultural original comienza a perder su carácter rígido y distintivo mientras surgeuna definición más flexible y amplia del yo "(p 391). Una vez adquirida esta etapa, el individuo llega a una "mayor autoconciencia y auto conciencia de la identidad" y participa en una "continua búsqueda de autenticidad en sí mismo y en otros a través de límites de grupo".

\subsubsection{La Reconstrucción de redes de apoyo}

El arte, en sus diferentes variedades, pero especialmente a través de la danza, la música y el teatro, ayuda a la comunicación interpersonal y a la sensación de confianza y corresponsabilidad con el grupo. El grupo se hace en la medida en que se crea algo entre todos, por todos. Imperceptiblemente, el acto de crear convoca la relación coral y debilita las cautelas que impone el pensamiento lógico. Crear convoca a diluir fronteras con el otro, cuando se crea con él. Por ello es un instrumento valioso en la reconstrucción de redes sociales y humanas, cunado éstas se han perdido o cuando todavía no se han encontrado.

\subsubsection{El Empoderamiento}

El empoderamiento se refiere al proceso por el cual los individuos, grupos, organizaciones y comunidades desarrollan un sentido de control sobre sus vidas, para 
actuar eficientemente en el ámbitopúblico, tener acceso a recursos y promover cambios en sus contextos comunes. El empoderamiento, como un proceso a través del cual la gente gana un mayor control sobre decisiones y acciones que afectan a su salud, tiene tres dimensiones: la individual o personal, la organizacional y la comunitaria o colectiva.

La educación para el "empowerment" exige tomar seriamente en consideración las fortalezas, experiencias, estrategias y metas que tienen los miembros de los grupos pertenecientes a minoríasétnicas. También implica ayudar a estos grupos a analizar y comprender la estructura social y a desarrollar las capacidades necesarias que les posibiliten conseguir sus metas de forma satisfactoria.

El empoderamiento permite al sujeto la mejora de la autoestima, el desarrollo personal, la dignidad o la toma de conciencia de sí mismo, elementos constitutivos que enriquecen el enfoque del empoderamiento, el cual persigue el objetivo de aumentar la participación individual, como ciudadano, y colectiva, en movimientos o redes sociales activas.

El arte, a través del manejo de técnicas cada vez más refinadas permite desarrollar el sentimiento de "ser capaz", a la vez que proporciona un sentimiento de satisfacción y bienestar tras la obra conseguida. El arte comunitario permite compartir la sensación de control común, de objetivo común logrado, y puede ayudar a tal fin.

\subsection{Experiencias}

Con todo este bagaje teórico y metodológico se proyectaron diferentes talleres pilotos que pusiesen en práctica lo que habíamos desarrollado y asentado desde la teoría. Bajo el nombre genérico "Sentirse en casa", las propuestas fueron diversas:

- "Acción/creación", dirigido a personas que esperan el estatuto de refugiados en la Comisión de ayuda al Refugiado, realizado por Berta de la Dehesa y Tania Ugena;

- El taller "El encuentro de crear", con la Asociación la Rueca, realizado por Ana rosa Sánchez Velasco.

- El taller con mujeres magrebíes, que llevaba varios años funcionando, de la Asociación Ventillarte, a cargo de Laura Rico Caballo.

- El taller para la reagrupación de familiar emigrantes, en el Ayuntamiento de San Sebastián de los Reyes, en Madrid, a cargo de Esther Carmona y Carolina Peral.

- y un taller, "Biografías de tu territorio", con la Asociación La rueca, dirigido a mujeres inmigrantes y realizado por Marián López Fdz. Cao y Ana Rosa Sánchez.

\subsubsection{Unos apuntes sobre los registros de observación}

Lasarteterapeutas/talleristas son también creadoras, y son sujetos que experimentan emociones, afectos. Son, en definitiva, sujetos encarnados, en palabras de SheylaBehabit y observan desde un lugar, que es también lugar cognitivo y afectivo. Recogiendo los aportes de la A/R/Tography, terminología acuñada por Rita Irwiing y colaboradores, las talleristas se conforman como artistas, investigadoras y educadoras o terapeutas, desde su localización cognitiva y afectiva. Su situación de creadoras les permite comprender la creación de los otros, sus procesos y dificultades. 
Como investigadoras, en el proceso de observación participante, comprenden las dinámicas de la evidencia práctica que revierten de nuevo en el diseño y reflexión teórica sobre los fundamentos. Como terapeutas, comprenden las dinámicas usuario/facilitador/espacio de terapia-creación que fluye a través de los procesos trans y contratransferenciales. Desde esa localización, con sus biografías y espacios específicos, observan. Por ello la observación debe, en la medida de lo posible recoger también esa intrincada relación de sujetos vinculados, ese cruce de narrativas, de los distintos yoesdramatúrgicos y de los yoespresentes en cada interrelación.

Reflexionar sobre cómo observar tomó gran parte de nuestro tiempo de diseño y reflexión: con o sin pre-test y post-test, con o sin grabadora, con o sin video, ... Cada uno de los registros por los que optemos puede contribuir a intimidar/nos, activar resistencias en los otros y en nosotros, revivir antiguas y nuevas desconfianzas, sentimientos de control y engaño. El cómo es, en la intervención psicosocial a través del arte, tan importante como el qué, porque todo lo que suceda es significativo y digno de observación y análisis. Los instrumentos de observación actúan a veces como metáforas del poder desigual que las personas migrantes tienen con respecto a las personas nativas, donde sólo las personas migrantes son las susceptibles de observación y análisis ¿por qué, por ejemplo, no son comunes los pre y post tests sobre percepción que el o la facilitadora tiene de los migrantes antes y después de hacer el taller? ¿Abren su relación a personas de otras culturas después de coordinar un taller?, ¿Les ayuda el taller a reconsiderar su autopercepción?, serían interesantes preguntas para realizar.

Optamos finalmente por el diario de campo donde se recogiesen rastros de evidencias y reflexiones que tenían que ver con el proceso y con la imbricación del sentir/conocer-se/crear/vincular la experiencia vital transcurrida en el taller.

Si el acompañamiento en el taller, como hemos señalado en líneas anteriores debe ser cuidadoso, sutil, delicado, si debe constituirse en entonación afectiva, comunión, que sólo parta del respeto y la no intromisión, los instrumentos de observación y evaluación deben ser coherentes con estos principios de respeto humano. Si el acompañamiento no dirige, sino que se sitúa al lado del sujeto y ofrece un espacio de seguridad y bienestar, desde donde proyectar, enfrentarse a los miedos y transformarse, el modo de registro debe ser cualquier cosa menos un juicio al otro. Debe aportar elementos que nos ayuden a ponernos en el lugar del otro y desde ahí, proporcionar elementos que ayuden a comprender y reconstruir su proyecto de vida.

La observación, consecuente con lo anterior, ha de estar marcada, igualmente, por la delicadeza. Optamos por animar al registro visual conjunto, de participantes y facilitadores a la fotografía de unos y otros, participantes y facilitadores, y por la confección, a posteriori, de un cuaderno, de los facilitadores y de los participantes, que reflejara las inquietudes y se constituyera asimismo como una nueva creación: la del tallerista que experiencia también el taller a través de sus emociones, su cuerpo, sus manos que dibujan las huellas de la experiencia.

Optamos por invitar a las participantes a la confección de un video que diera cuenta de lo vivido. 
Siguiendo los objetivos, utilizamos la ayuda de una parrilla de observación que ayudase a recordar aspectos que podían haberse eludido u olvidado en el relato de campo. Estos indicadores de observación (anexo final), funcionaban como pequeños avisos sobre qué aspectos podían haberse pasado por alto u olvidados y eran muy útiles, a la hora de hacer una observación conjunta del proceso que no obviara pequeños elementos que a veces nos podían proporcionar aspectos sobre su autopercepción, la percepción del entorno y sus modos de reacción. Ello, unido a una supervisión continua de un tercero, nos ofreció un multimétodo que combinado suplía las deficiencias de uno u otro método y ampliaba una percepción más democrática e igualitaria entre facilitadores y participantes.

Nos dimos cuenta de que los pre y post tests escritos se fueron alejando de nuestros objetivos, a pesar de la buena voluntad que les inspiraba. Enfrentar a una persona recién llegada a un espacio de creación a formatos similares a los policiales, aportaba en casos desconfianza, sino resquemor, que destruía la incipiente confianza con la que llegaban. Responder en un grado del uno a cinco a cuestiones sobre el bienestar antes y después no nos aportaba la información que requeríamos para evaluar el taller, cuando buscábamos algo más profundo que atañía a los sentimientos, afectos, percepciones del ser en un nuevo lugar. Responder a preguntas básicas y prácticas, cuando durante el taller habíamos hablado de aspectos muy íntimos y personales parecía simplificar y hacer banal momentos de gran confianza e interconexión.

Porque, en definitiva, lo que encontramos en las participantes fue una búsqueda de sí mismas, más allá de una adquisición concreta de una capacidad específica, una modificación de conducta o una gestión de recursos, haciendo referencia a las primeras páginas de este texto.

Finalmente, la utilización de la entrevista abierta nos proporcionó una evaluación del taller mucho más apurada y en detalle, que cualquier formulario programado.

\section{REFERENCIAS BIBLIOGRÁFICAS}

BOWLBY, J. (1969), Attachment and loss, Vol. 1: Attachment. New York: Basic Books.

CASTORIADIS, C. 1987. The Imaginary Institution of Society. Cambridge: Polity Press.

FEMENÍAS, M.L: 2007, pp18)

FIORINI, H. 1995. El psiquismo creador. Barcelona, Paidós.

GOLDMAN, EMMA (1931) Living my life. Downlowded 21 june 2012: http://dwardmac.pitzer.edu/Anarchist_Archives/goldman/living/livingtoc.html

HARAWAY, D. Simians, Cyborgs and Women: The Reinvention of Nature (New York; Routledge, 1991.

International Journal of Group Tensions, Vol. 30, No. 1, pp. 81-105. 
Irwin, Rita L. \&Springgay, S. (2008) "A/r/tography as practice based research". In Springgay, S., Irwin, Rita L., Leggo, C. \&Gouzouasis, P. (Eds.) Beingwith A/r/tography. (pp. xiii-xvii) Rotterdam, The Netherlands. Sense Publishers.

GARCÍA ROCA, JOAQUÍN (2010) "Enfoque psicosocial e incidencia pública. Las necesarias transiciones". En Melero, L. La persona más allá de la migración, pp. 17-31.

MARCEL STOETZLERANDNIRAYUVAL-DAVIS (2002) "Stand point theory, situated knowledge and the situated imagination" Feminist Theory 2002; 3; 315, DOI: $10.1177 / 146470002762492024$

MARCUSE, H. (1991) One-dimensional man. London: Routledge.

MARISELA MONTENEGRO MARTÍNEZ \& JOAN PUJOL TARRÈSCONOCIMIENTO SITUADO Y ACCIÓN RevInteramPsicol 37(2), 2003

MELERO VALDÉS, L. (coord.) (2010) La Persona más allá de la Migración (ISBN: 978-84-9876-999-9).

SPINOZA, B. ([1677] 1993). Ethics and treatise on the correction of the intellect. (A. Boyle,

STENNER, P. ,BROWN, S.D. (2001)“Being affected: Spinoza and the psychology ofemotion"

STERN, D. (1985)The Interpersonal Worldof the Infant. A View from Psychoanalysis and Developmental Psychology. New York: Basic Books, Inc., Publishers.

STOETZLER, M., YUVAL-DAVIS N. (2002) Stand point theory, situated knowledge and the situate dimagination. Feminist Theory December 2002 3: 315-333. 


\section{ANEXO I}

\section{FICHA DE REGISTRO}

NOMBRE

\section{$\mathrm{N}^{\circ}$ SESIÓN}

\section{FECHA}

Categorías de análisis:

- Incertidumbre

- Tolerancia a la frustración

- Ansiedad

- Pérdida de orígenes/identidad/geografías

- Apropiación/integración/interacción de nuevas identidades/contextos

- Reconstrucción de redes vinculares

- Aumento de seguridad en sí misma/o, sentimiento de control sobre su propia vida.

\begin{tabular}{|l|l|l|l|l|l|l|}
\hline PROCESO & 1 & 2 & 3 & 4 & 5 & \\
\hline $\begin{array}{l}\text { Se adapta al nuevo mate- } \\
\text { rial/técnica }\end{array}$ & & & & & & Le cuesta adaptarse, se irrita \\
\hline Se toma su tiempo & & & & & & Lo hace deprisa \\
\hline Confía en sus capacidades & & & & & & Preocupada/o por sus errores \\
\hline Concentración, & & & & & & Parece distraído/a \\
\hline Valoriza su ejecución & & & & & & Desvaloriza su ejecución \\
\hline Mantiene interés & & & & & & Abandona con facilidad \\
\hline Independiente en el trabajo & & & & & & Dependiente en el trabajo \\
\hline Tranquilidad & & & & & & Inquietud \\
\hline Elige con confianza & & & & & & No se puede decidir \\
\hline $\begin{array}{l}\text { Cuando no tiene éxito sigue in- } \\
\text { tentándolo }\end{array}$ & & & & & & $\begin{array}{l}\text { Cuando no tiene éxito se detie- } \\
\text { ne }\end{array}$ \\
\hline $\begin{array}{l}\text { Es capaz de asumir los riesgos } \\
\text { que implica una tarea nueva }\end{array}$ & & & & & & $\begin{array}{l}\text { No asume los riesgos o le cues- } \\
\text { ta mucho. }\end{array}$ \\
\hline Actitud corporal abierta. & & & & & & Actitud corporal cerrada. \\
\hline OBSERVACIÓN & & & \\
\hline
\end{tabular}




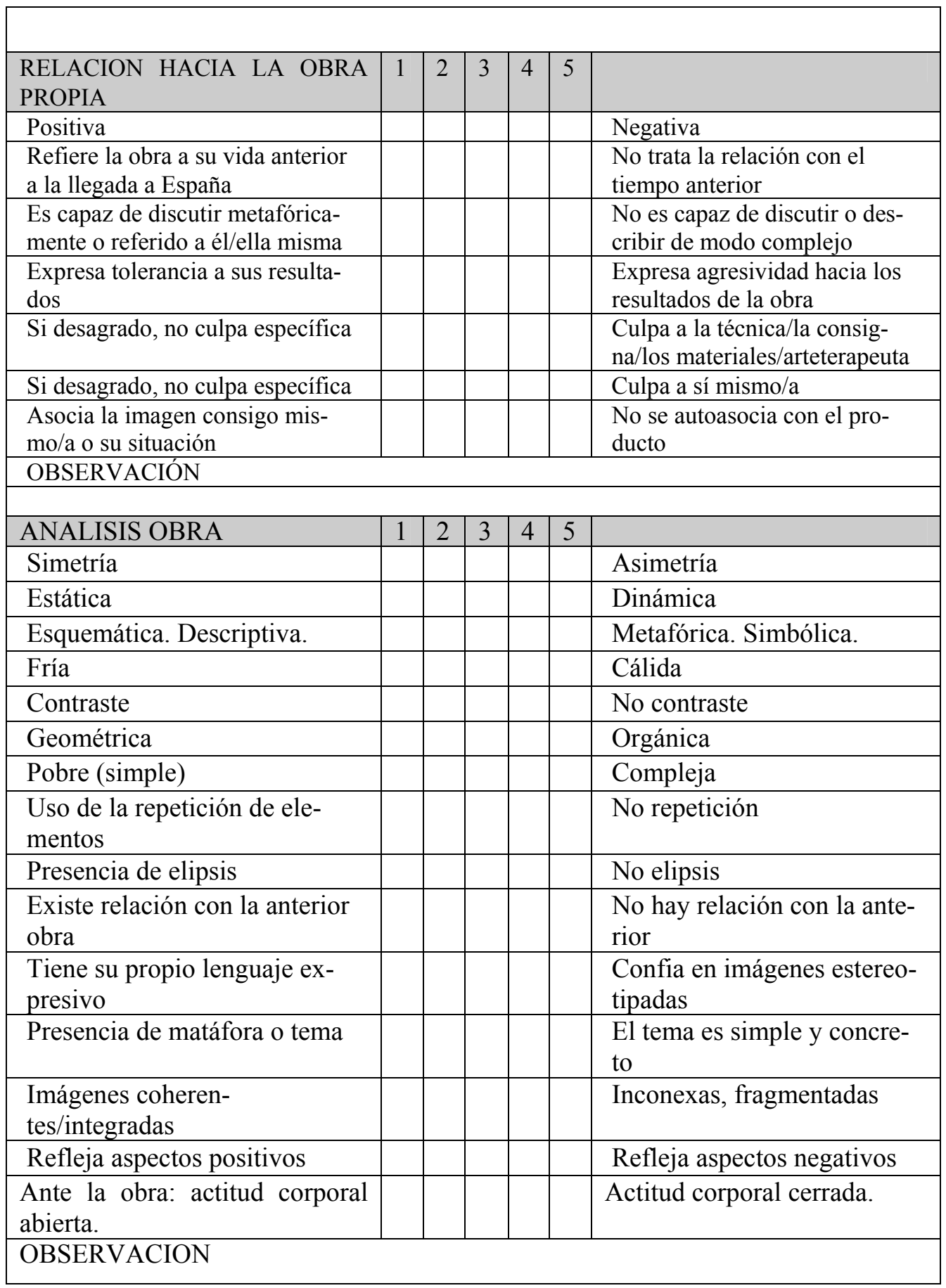




\begin{tabular}{|c|c|c|c|c|c|c|}
\hline INTERACCIÓN & 1 & 2 & 3 & 4 & 5 & \\
\hline $\begin{array}{l}\text { Se relaciona con confianza con los } \\
\text { demás }\end{array}$ & & & & & & Muestra inhibición/desconfianza \\
\hline Es participativo/a & & & & & & Se aisla \\
\hline Comparte adecuadamente & & & & & & Incapaz de compartir \\
\hline Mantiene su propios espacio físico & & & & & & $\begin{array}{l}\text { Entra inapropiadamente en el } \\
\text { espacio personal de los demás }\end{array}$ \\
\hline Responde/acepta los límites & & & & & & $\begin{array}{l}\text { Dificultad de responder a los } \\
\text { límites }\end{array}$ \\
\hline Autónoma/o. & & & & & & Busca la aprobación/refuerzo. \\
\hline Se revela contra la autoridad. & & & & & & Es sumiso. \\
\hline Pide opinión sobre sí. & & & & & & No acepta comentarios. \\
\hline Sostiene la mirada. & & & & & & Mirada huidiza. \\
\hline $\begin{array}{l}\text { Cuando se equivoca asume su } \\
\text { responsabilidad. }\end{array}$ & & & & & & $\begin{array}{l}\text { Cuando se equivoca niega su } \\
\text { responsabilidad o culpa a los } \\
\text { demás. }\end{array}$ \\
\hline Actitud corporal abierta. & & & & & & Actitud corporal cerrada. \\
\hline OBSERVACIÓN & & & & & & \\
\hline
\end{tabular}

